\title{
Distribution of common pathogens in patients with pyogenic liver abscess in China: a meta-analysis
}

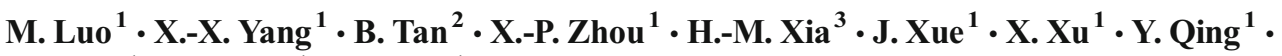 \\ C.-R. $\mathrm{Li}^{1} \cdot$ J.-F. Qiu ${ }^{1} \cdot$ Y.-L. $\mathbf{L i}^{1}$
}

Received: 8 April 2016 / Accepted: 16 June 2016 / Published online: 11 July 2016

(C) The Author(s) 2016. This article is published with open access at Springerlink.com

\begin{abstract}
Pyogenic liver abscess (PLA) is a potentially lifethreatening disease in many parts of the world, especially in Asia. The aim of this study was to quantify the proportion of common pathogens in patients with PLA in China, using a meta-analysis method based on systematic review of published studies. Several electronic databases were searched to identify the studies reporting the pathogens of PLA. We performed a meta-analysis to calculate the pooled proportion of pathogens and subgroup analysis among the included studies using R 3.1.1 software. In total, 183 studies were included in our final analysis, Klebsiella spp (54\%), Escherichia spp (29\%), Enterobacter spp (9\%), Proteus spp (6\%) and Pseudomonas spp (5\%) comprised the major gram-negative bacteria. Gram-positive bacteria mainly included Staphylococcus spp (13\%), Streptococcus spp (8\%) and Enterococcus spp $(7 \%)$. The distribution of pathogens in PLA patients were different in different economic regions in China. The proportion of Klebsiella spp had an upward tendency in recent years compared to other pathogens. In addition, the proportion of common pathogens in PLA patients with diabetes mellitus (DM) were carried out indicating that the dominant pathogens were Klebsiella spp (66\%), Escherichia spp (21\%) and Enterobacter spp (11\%). This meta-analysis showed that the main pathogens of PLA were
\end{abstract}

Y.-L. Li

liylyl@126.com

1 School of Public Health and Management, Chongqing Medical University, Chongqing 400016, China

2 Yubei District Center for Disease Control and Prevention, Chongqing 401120, China

3 School of Medicine, Johns Hopkins University, Baltimore, MD, USA
Klebsiella spp, Escherichia spp, Staphylococcus spp, and Enterobacter spp in China. To ensure a precise estimate of the epidemiology of the pathogens, further large-scale or even a population-based study is needed.

\section{Introduction}

Pyogenic liver abscess (PLA) is a potentially life-threatening disease, which has been reported in many countries [1-7]. The morbidity of PLA has been increasing steadily in the past few decades, and although the mortality decreased slightly, PLA remains a disease with significant mortality [1, 5, 8-11]. Among others, surgical intervention and appropriate antibiotics combined with the US-guided percutaneous drainage of liver abscess constitute major treatments and increase the chances of survival $[12,13]$. The diagnosis of PLA is based on clinical features, evidence from imaging studies and microbiology. Unfortunately, the diagnosis of PLA is technically challenging, due to the fact that the symptom presentation is nonspecific [14]. The disease was more prone to run a lethal course if without appropriate treatment. Accurate identification of pathogens was important for early appropriate patient management. There is a chance of false negative detection when the patient received prior antibiotic treatments. When the diagnosis of PLA was suspected, broad-spectrum antibiotics will be started immediately to control ongoing bacteremia and its associated catastrophic complications including metastatic endophthalmitis and central nervous system infections $[12,15,16]$. Knowing the etiology of PLA, when possible, plays an important role in the successful therapy of PLA patients. The pathogens causing PLA are geographically diverse $[1,2,11,17]$. In China, the major pathogen causing PLA is Klebsiella pneumoniae (K. pneumoniae) [5, 8]. To date, besides K. pneumoniae, other bacterial etiologies of PLA were 
lacking large epidemiological data. Diabetes mellitus (DM) is at increased risk for common infections $[18,19]$ and is a wellknown risk factor for PLA [4], with reported co-existence rates of $48 \%$ in Taiwan [20]. However, it is unclear whether there is a difference in the pathogens in PLA patients with DM. In order to summarize the distribution of pathogens of PLA in China, this would be used to guide clinicians in therapy decisions and the direction of the future research. We systematically searched the literature about the pathogens of PLA, described the main pathogens of PLA, the distribution of pathogens in different economic regions, the change trend of pathogens in recent years and the common pathogens in PLA patients with DM.

\section{Materials and methods}

\section{Search strategy}

We searched through the electronic databases PubMed, EMBASE, Highwire, Web of Science, China National Knowledge Infrastructure (CNKI), China Biological Medical Database (CBM), VIP Database for Chinese Technical Periodical (VIP) and Wanfang database using the following search terms: "liver abscess, hepatic disease, hepatic abscess, welling-abscess of the liver" and "etiology, pathogen, pathogens, pathogenic microorganisms, bacteria". The references were also manually searched to identify additional relevant publications. All studies related to the pathogens of PLA were published from January 1, 2004 to March 1, 2015, with a second search done on September 20, 2015. We restricted our search to publications in English and Chinese.

Studies were included if: (1) The study was about PLA and pathogens, (2) The diagnosis of PLA was based upon clinical features, evidence from imaging studies (ultrasound or computed tomography), as well as microbiology (blood or abscess culture results); Liver abscess with demonstrated positive amoebic or hydatid serology were excluded [14], (3) Patients with diabetes were diagnosed according to World Health Organization (WHO) criteria [21], (4) The study regions were in China. The following studies were excluded: (1) Identical studies retrieved through different databases, (2) Editorials, reviews or conference articles, (3) The articles had incomplete information to calculate the proportion of pathogens.

\section{Study selection and data extraction}

Based on these explicit criteria, two researchers independently performed the initial screening of title and abstract, whereby disagreements were resolved by reaching a consensus. These original articles were then retrieved and the full text screened for final inclusion and data extraction.
Two researchers independently extracted data from all of the included studies with Excel 2007 (Microsoft Corp, Redmond, WA). For each accepted study, the following data were abstracted: first author, study region and time, year of publication, sample size, methods of specimens' cultures, the number and type of positive strains. The different kinds of strains were combined on the basis of Bergey's Manual of Systematic Bacteriology.

\section{Statistical analysis}

The pooled proportion of pathogens and their $95 \%$ confidence intervals (CIs) were used in our study. All statistical analysis was conducted using the meta package of $\mathrm{R}$ 3.1.1 (Bell Laboratories); metaprop, metabias and metainf were chosen for analysis. The logit transformation was chosen to calculate the pooled proportion of pathogens among the included studies. Subgroup analysis focused on different economic regions and years. Heterogeneity was assessed by Qtest and $I^{2}$ statistics [22]. If high and significant heterogeneity was detected across studies $\left(p<0.05, I^{2}>50 \%\right)$ a random effect model was used, otherwise, a fix effect model was used. Sensitivity analysis was performed to evaluate the stability of the meta-analysis result. Egger's linear regression test [23] was used to statistically assess the publication bias $(p>0.05$ was considered to have no publication bias).

\section{Results}

\section{Study selection and characteristics}

A flowchart of the study identification and selection process was presented in Fig. 1. We identified 2,418 publications from eight electronic databases according to our search strategy and three publications from manually searched. A total of 1,097 publications were excluded due to duplicate publications. After screening of title and abstract, 591 publications were excluded. A total of 550 studies were excluded after full-text screening due to lack of adequate data, with subjects not Chinese, reviews or reports, duplicates, or not in accord with the diagnostic criteria of PLA. Finally, 183 studies were included in this meta-analysis, among them, 57 studies reported the pathogens of PLA patients with DM and were included in further analysis.

These 183 studies reported data on 6,913 strains of 6,347 subjects in the 31 provinces of China. Among them, six studies which included 1,215 patients with PLA were published in English, and the other studies were published in Chinese. There were no appropriate studies included in this metaanalysis in the three provinces: Macao, Qinghai and Tibet. The largest number of the included studies of province was Jiangsu (23 studies), followed by Zhejiang (20 studies), 
Fig. 1 The PRISMA flowchart of the study identification and selection. PLA pyogenic liver abscess

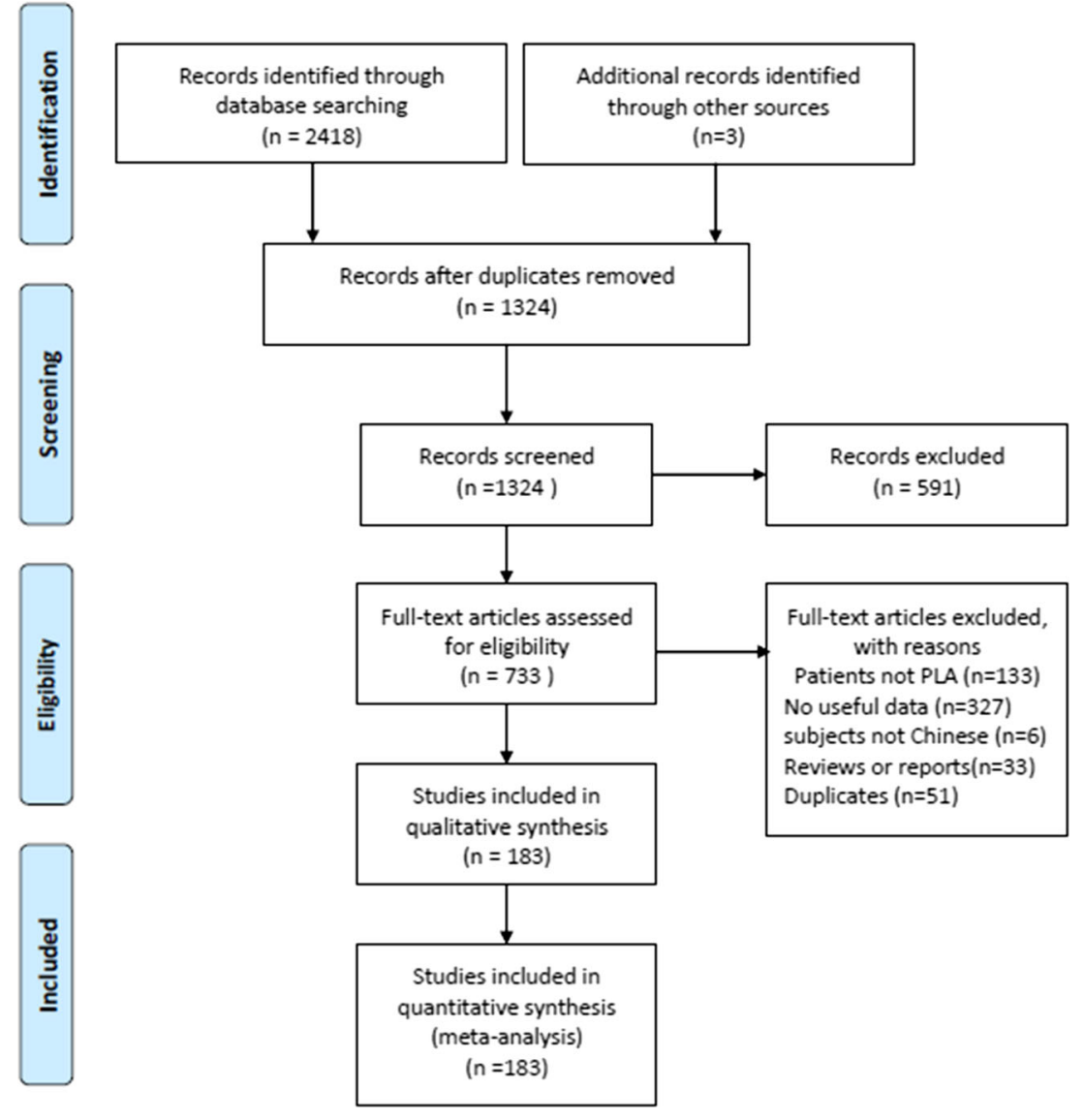

Shanghai (14 studies), Liaoning (13 studies), Beijing (11 studies) and so on. Sample size of those studies ranged from 2 to 301. The result of abscess culture was extracted in $71 \%$ of the included studies, there were those with a small proportion (11\%) of the blood culture, and methods of specimen cultures were unknown accounted for $23 \%$. They were published from January 1, 2004 to September 20, 2015.

\section{The pooled proportion of pathogens}

For all included studies, when available, the proportion of pathogens was calculated and showed in Fig. 2 by metaanalysis methods with R 3.1 .1 software. Klebsiella spp (54\%), Escherichia spp (29\%), Enterobacter spp (9\%), Proteus spp (6\%) and Pseudomonas spp (5\%) comprised the major gram-negative bacteria. The proportion of Klebsiella spp was much higher than that of other pathogens causing PLA. Gram-positive bacteria mainly included Staphylococcus spp (13\%), Streptococcus spp (8\%) and Enterococcus spp (7\%).

K. pneumoniae accounted for $93 \%$ of Klebsiella spp and was the most common microorganism isolated from PLA patients. Staphylococcus aureus accounted for $88 \%$ of Streptococcus spp and was the most common gram-positive bacteria, the specific bacteria was one of the other bacterial species not shown in this study. The proportion of other pathogens was less than $1 \%$, and we put them into other gramnegative bacteria or gram-positive bacteria. Some studies were only provided the number of pathogens and not the type, which we put into other bacteria.

\section{Distribution of pathogens in different economic regions}

We performed subgroup analysis in different economic regions with several common microorganisms. According to the conception of economic regional division during the 11th Five-Year Plan, the China mainland was divided into four economic regions, which included Northeast (Liaoning, Jilin and Heilongjiang), East (Beijing, Tianjin, Hebei, Shanghai, Jiangsu, Zhejiang, Fujian, Shandong, Guangdong and Hainan), Middle (Shanxi, Anhui, Jiangxi, Henan, Hubei and Hunan) and West regions (Inner Mongolia, Guangxi, Chongqing, Sichuan, Guizhou, Yunnan, Shaanxi, Gansu, Qinghai, Ningxia, Xinjiang and Tibet). We classified Taiwan and Hong Kong as another region. In total, China was divided into five regions. The GDP (gross domestic product) and GRP (gross regional product) per capita were used as indicators of economic status of each economic region. The annual data of GDP and GRP per capita of each province in China from 2004 to 2014 were retrieved by querying the National Bureau of 
Fig. 2 The histogram of common pathogens in patients with pyogenic liver abscess

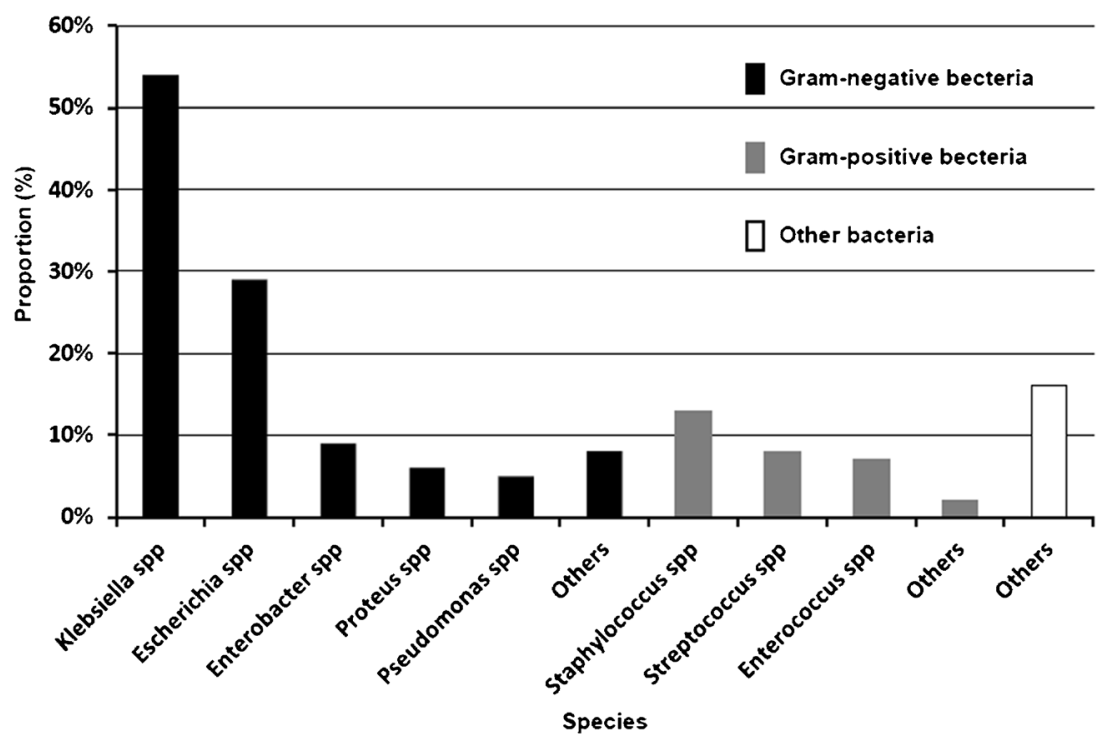

Statistics of China website or from the yearbooks of the local Bureau of Statistics. According to the average of GRP per capita from high to low, the order of the economic regions would be the Region A: Taiwan and Hong Kong, Region B: East economic region, Region C: Northeast economic region, Region D: Middle economic region, Region E: West economic region. The economic status of five economic regions is shown in Table 1. We performed subgroup analysis with several common microorganisms in different economic regions. The Forest plot for the proportion of Klebsiella spp in different economic regions is shown in Fig. 3. The highest proportion of Klebsiella spp (70 \%) was in the A region including Taiwan and Hong Kong, whereas the lowest was $42 \%$ in the E region (West economic region).

Eight common pathogens of PLA in different economic regions were summarized in Fig. 4, which has been calculated separately by meta-analysis methods with R 3.1.1 software. The results indicated that Klebsiella spp, Escherichia spp and Staphylococcus spp were the main pathogens in the East and Middle economic regions; however, the dominant pathogens were Klebsiella spp, Escherichia spp and Enterobacter spp in the Northeast and West economic regions. In Taiwan and Hong Kong, these were Klebsiella spp, Escherichia spp and

Table 1 Economic status of five regions in China (the average from 2004 to 2014)

\begin{tabular}{lll}
\hline Economic region & $\begin{array}{l}\text { Total GDP } \\
\text { (Hundred million RMB) }\end{array}$ & $\begin{array}{l}\text { GRP per capita } \\
\text { (RMB 10,000/person) }\end{array}$ \\
\hline Northeast & $11,517.86$ & 3.11 \\
East & $21,252.84$ & 4.61 \\
Middle & $13,235.57$ & 2.23 \\
West & $6,365.48$ & 2.19 \\
Taiwan, Hong Kong & $23,395.99$ & 18.00 \\
\hline
\end{tabular}

Streptococcus spp. The frequency of Klebsiella spp infection is shown in Fig. 4, which suggested that it was consistent with the level of regional economic development. However, lower economic regions have a higher frequency of Escherichia spp infection than the higher economic regions.

\section{The trend of pathogens in recent years}

We performed subgroup analysis in different years with four common microorganisms by meta-analysis methods with $\mathrm{R}$ 3.1.1 software, and the result is shown in Fig. 5. We did a search on September 20, 2015, so the data of pathogens in 2015 was incomplete. Between 2004 and 2015, the change trend of Escherichia spp, Staphylococcus spp and Streptococcus spp was stable, ranging from $16 \%$ to $39 \%$, $6 \%$ to $22 \%$, and $4 \%$ to $15 \%$, respectively. Meanwhile, between 2004 and 2015, Klebsiella spp had an upward tendency, whereby the highest pooled proportion of Klebsiella spp was $71 \%$ in 2009. The lowest was $38 \%$ in 2006.

\section{The common pathogens in PLA patients with Diabetes mellitus}

We pooled the common pathogens of PLA patients with diabetes mellitus (DM). As shown in Fig. 6, the dominant pathogens were gram-negative bacteria including Klebsiella spp (66\%), Escherichia spp (21\%) and Enterobacter spp (11\%). There is a difference in the pathogens in PLA patients with DM. This was shown as the proportion of Klebsiella spp and Enterobacter spp were higher and that of Escherichia spp and Staphylococcus spp were lower. Enterobacter spp was more than Staphylococcus spp, which became the third most common pathogen in PLA patients with DM after those of Klebsiella spp and Escherichia spp. 


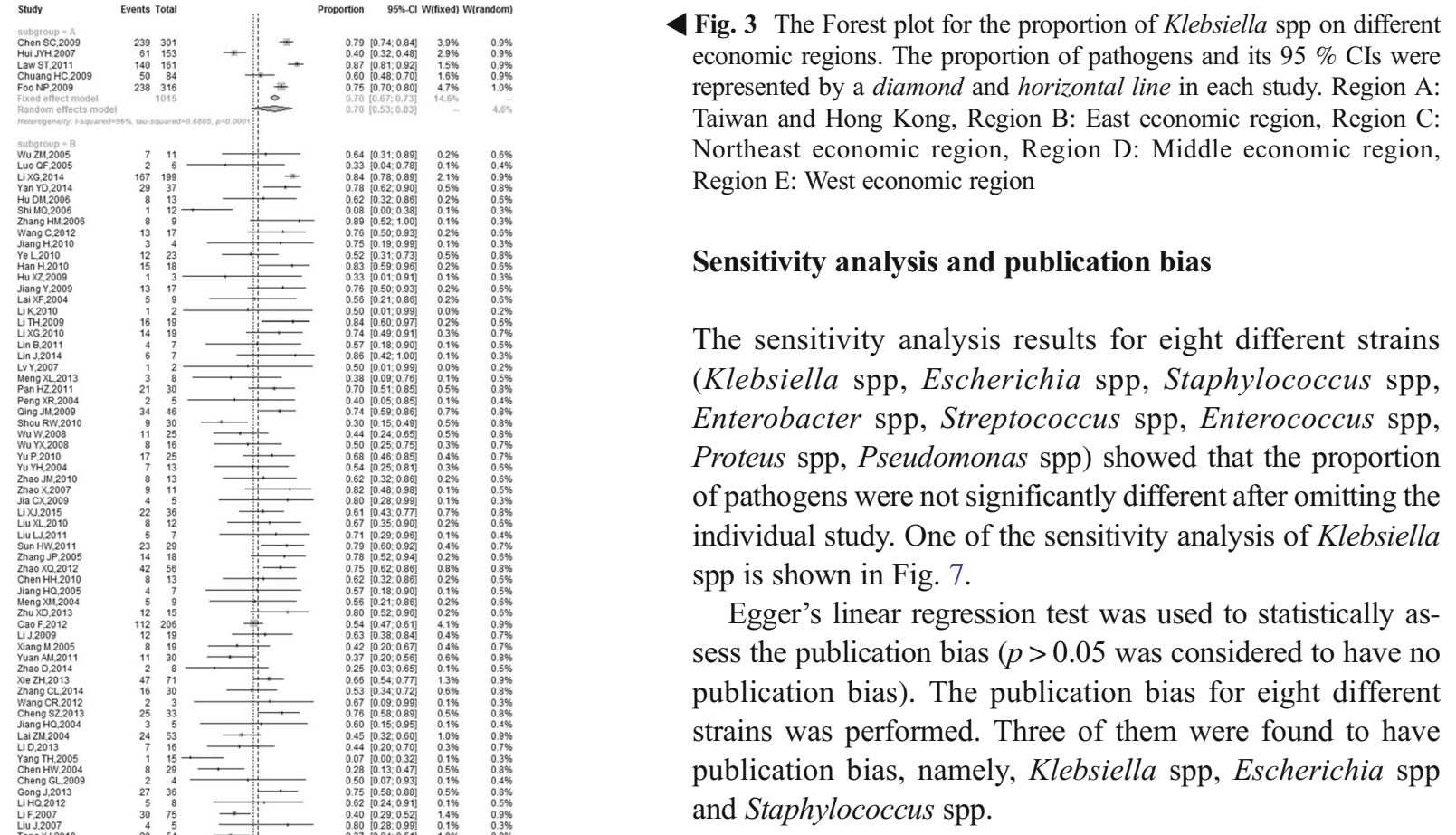

\section{Discussion}

Pyogenic liver abscess (PLA) is a suppurative infection of the hepatic parenchyma, which can develop severe complications including metastatic endophthalmitis and central nervous system infections $[15,16]$, and patients with PLA have higher rates of primary liver cancer and gastrointestinal cancer [24, 25]. In China, the morbidity of PLA was increasing steadily in the past few decades. A comprehensive study on the pathogens of PLA has not been reported. A cross-sectional survey does not always reach this target due to its flaw in methodology [26]. Meta-analysis is a statistical method whereby data from a number of studies can be pooled to produce reliable data. This study was the first to demonstrate a relatively comprehensive evaluation of the pathogens of PLA in China. A total of 183 studies were enrolled by meta-analysis method, with inclusion of data from $91 \%$ of the provinces in China. Although they did not provide drug sensitivity results for antibiotics, knowing the etiological distribution of PLA is informative in facilitating clinicians to identify appropriate treatments for this suspicious PLA patient with the negative results of bacteria cultures.

The available data suggested that Klebsiella spp was the most common microorganism isolated from PLA patients; after Klebsiella spp, Escherichia spp was the second pathogen causing PLA. In addition, Staphylococcus spp, Enterobacter spp, Streptococcus spp and Enterococcus spp were also common pathogens of PLA. It has been reported that the mortality rate of non- K. pneumoniae liver abscess was higher than that of $K$. pneumonia [27, 28]. Community-acquired methicillin 
Fig. 4 The histogram of pathogens of pyogenic liver abscess in different economic regions. Region A: Taiwan and Hong Kong, Region B: East economic region, Region $\mathrm{C}$ : Northeast economic region, Region D: Middle economic region, Region E: West economic region

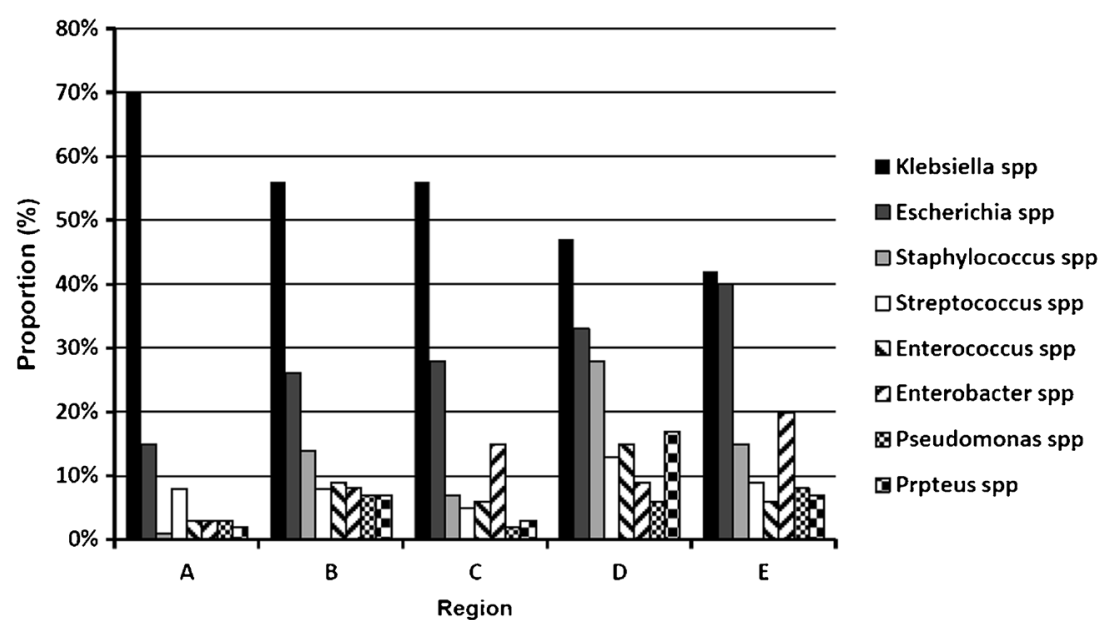

resistant Staphylococcus aureus liver abscesses had been reported in Hong Kong [29]. In contrast to K. pneumoniae, we should also pay attention to other pathogens of PLA in order to reduce the mortality.

We further quantitatively estimated the proportion of pathogens in subgroups defined by regions and years. This meta-analysis indicated that the most common pathogens were Klebsiella spp in different economic regions. The proportion of Klebsiella spp is $70 \%$ in Taiwan and Hong Kong. K. pneumoniae liver abscess (KPLA) is common [5] and has a high economic burden in Taiwan [30]. Fung [31] reported that intestinal colonization of virulent type $K$. pneumoniae is highly associated with PLA. Chinese ethnicity itself might be a major factor predisposing to intestinal colonization by K. pneumoniae [32]. It is probably the reason why there are so many cases of KPLA in China. It has been reported that diabetes mellitus (DM) is a more significant risk factor for the K. pneumoniae liver abscess than for the non-Klebsiella liver abscess [33]; the prevalence of DM was consistent with the level of regional economic development [34]. This may be one of the reasons why higher economic regions have a greater frequency of klebsiella infection than the lower economic groups. Additionally, Chen [35] reported KPLA are more prevalent in the cryptogenic liver abscesses. Future research should focus on the pathogenesis of KPLA to reduce the morbidity and economic burden.

This meta-analysis showed that Klebsiella spp had an upward tendency in China between 2004 and 2015. K. pneumoniae accounted for $93 \%$ of Klebsiella species. The widespread multiple drug-resistance and hypervirulent variant K. pneumoniae (hvKP) infections have increasingly caused serious global public health concern [36]; two changing trends in K. pneumoniae infections have been reported in China [37-39]. The management of infections due to $K$. pneumoniae has been complicated by the emergence of antimicrobial resistance, especially to the carbapenems, since these agents are often the last line of effective therapy available for the treatment of infections caused by multidrugresistant $K$. pneumoniae [40]. The epidemiology of new and
Fig. 5 Change trend of pathogens of pyogenic liver abscess in recent years

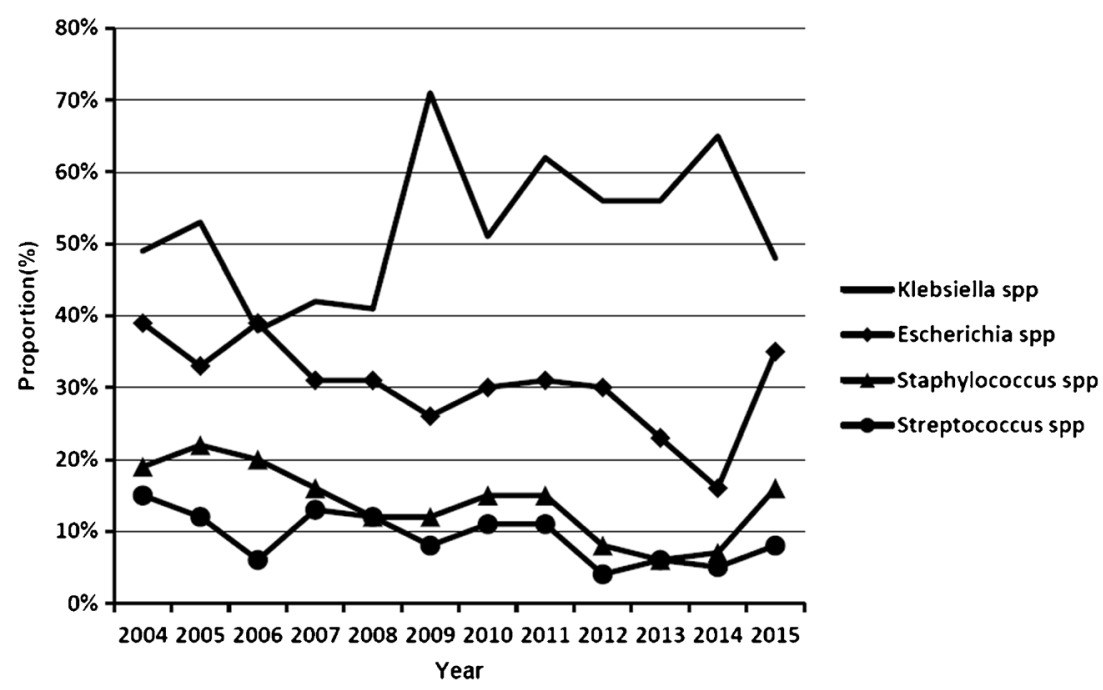


Fig. 6 Histogram of the common pathogens in PLA patients with DM. PLA pyogenic liver abscess, $D M$ diabetes mellitus. The pooled proportion of the pathogens are shown in Figure 6, where the results have been calculated separately by meta-analysis methods with R 3.1.1 software

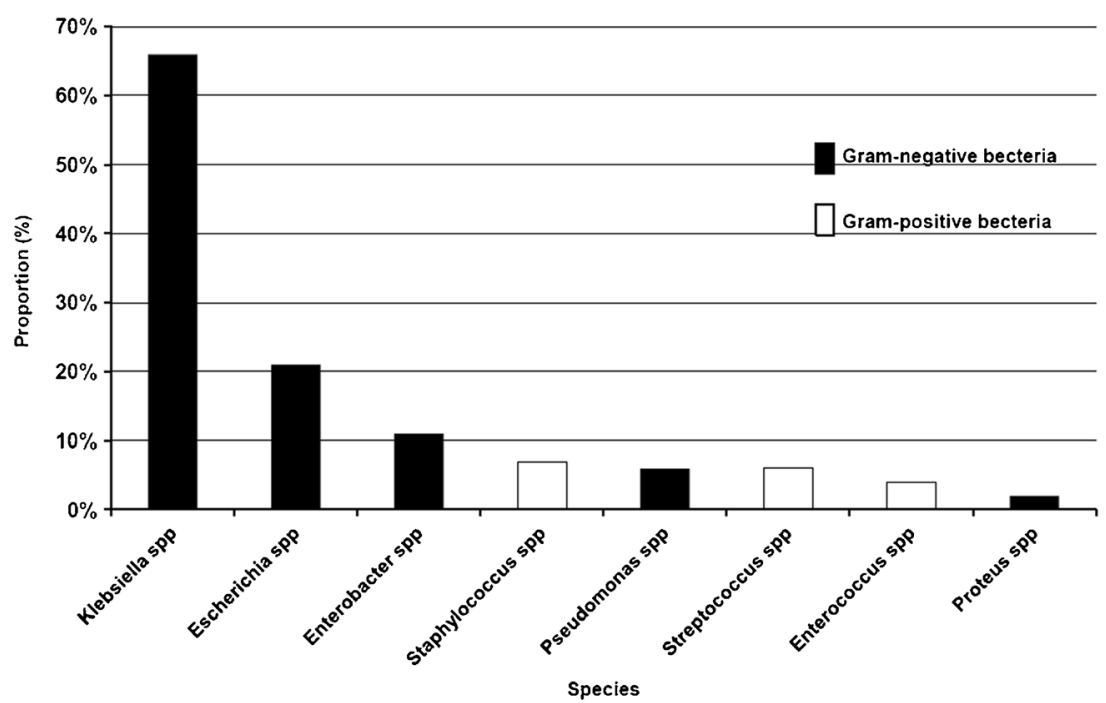

dangerous hvKP strains has had some recent advances, yet overall it remains poorly understood [41]. Enhancing our understanding of those multiple drug-resistance $K$. pneumoniae and hvKP is critical to make treatment decisions for KPLA patients.

Based on these data, the pooled data suggested that the proportion of Klebsiella spp and Enterobacter spp were higher and that of Escherichia spp and Staphylococcus spp were lower in PLA patients with DM. It has been reported that $\mathrm{DM}$ is a more significant risk factor for the K. pneumoniae liver abscess than for the non-Klebsiella liver abscess [33]. This may be the reason why the proportion of Klebsiella spp was higher in PLA patients with DM. One animal study suggested that the hypermucoviscosity-negative $K$. pneumoniae may serve as an ideal model for identifying virulence factors under diabetic conditions [42], which is convenient in further study of the pathogenesis of diabetes patients who are more susceptible to getting KPLA. DM is a significant risk factor for developing metastatic infections from PLA [43], such metastatic endophthalmitis and central nervous system infections could lead to a devastating outcome without a prompt and appropriate management. Although DM shows a higher association with PLA, it does not seem to increase the mortality of PLA [20]. Some previous studies have revealed that gasforming abscess, multi-drug resistant isolates, metastatic infection, and acute respiratory failure were associated with mortality of PLA [44, 45]. We need to identify other significant risk factors that increase the mortality of PLA; further studies should be followed to elucidate this issue.

The validity of original studies was influenced by many factors, which might affect meta-analysis [46]. Therefore, in these situations, combining data in a meta-analysis has to be performed with great care. However, there are still some limitations in our study. First, our study was limited by the incomplete collection of the pathogens data. Usually, a study has more than one specimens culture, the result including a more comprehensive number and type of pathogens than was extracted in our study, which causes inevitable loss of part of data. Furthermore, the pathogens of PLA include aerobic bacteria and anaerobic bacteria, the data of anaerobic bacteria was insufficient in the included studies, so we only reported the epidemiology of aerobic bacteria of PLA. Second, heterogeneity between studies still exists although we had a strict criterion to include the original literature. The sample size differs among the included studies, which may result in high heterogeneity. Third, there was publication bias in part of the reported outcomes. These cases reported from hospital were more than $90 \%$ in this meta-analysis, and clinicians might be affected by subjective factors in reporting these cases, which might contribute to publication bias. Moreover, with no gold standard of diagnosis, we used a diagnostic criteria base on the literature of Pang [14], in which the definition of PLA was comprehensive according to clinical features, evidence from imaging studies and microbiology. Therefore, some studies were excluded because diagnostic criteria were unclear, which might contribute to publication bias. Nevertheless, the usual methods for assessing publication bias using statistical tests are only applicable to randomized controlled trials or trials with matched controls and not to observational studies [47, 48]. Therefore, the results that apply the formal assessments of publication bias to this analysis might be inappropriate.

In conclusion, the main pathogens of PLA were Klebsiella spp, Escherichia spp, Staphylococcus spp, Enterobacter spp, Streptococcus spp and Enterococcus spp in China. The proportion of Klebsiella spp is much higher than other pathogens, especially in PLA patients with diabetes mellitus. It is informative during the study of etiology of PLA and making timely treatment decisions for suspicious PLA patients with the negative results of bacteria cultures. At the same time, the future research should concentrate on the pathogenic mechanism of 


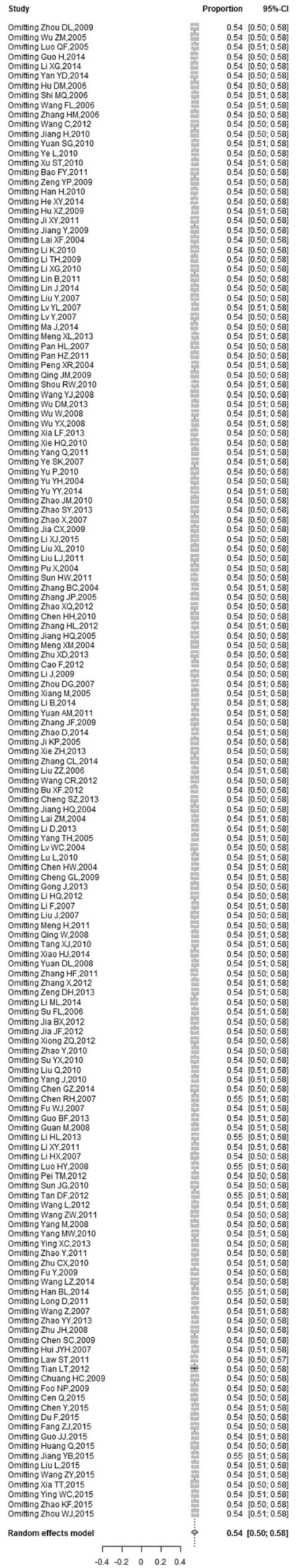

Fig. 7 The Forest plot of sensitivity analysis of the proportion of Klebsiella spp. The pooled proportion of pathogens and its $95 \% \mathrm{CIs}$ were represented with a diamond and horizontal line the main pathogens, the differential diagnosis of clinical pathological and physiological features, prognostic factors and so on, thus improving understanding of the burden of PLA. To ensure a precise estimate of the epidemiology of the pathogens, further large-scale or even a population-based study is needed.

\section{Compliance with ethical standards}

Funding The research leading to this manuscript has received funding from the National Natural Science Foundation of China (31200064).

Conflict of interest None.

Ethical approval Not required.

Informed consent All authors approved the final version of the manuscript.

Open Access This article is distributed under the terms of the Creative Commons Attribution 4.0 International License (http:// creativecommons.org/licenses/by/4.0/), which permits unrestricted use, distribution, and reproduction in any medium, provided you give appropriate credit to the original author(s) and the source, provide a link to the Creative Commons license, and indicate if changes were made.

\section{References}

1. Meddings L, Myers RP, Hubbard J, Shaheen AA, Laupland KB, Dixon E, Coffin C, Kaplan GG (2010) A population-based study of pyogenic liver abscesses in the United States: incidence, mortality, and temporal trends. Am J Gastroenterol 105:117-124

2. Mangukiya DO, Darshan JR, Kanani VK, Gupta ST (2012) A prospective series case study of pyogenic liver abscess: recent trands in etiology and management. Indian J Surg 74:385-390

3. Qu TT, Zhou JC, Jiang Y, Shi KR, Li B, Shen P, Wei ZQ, Yu YS (2015) Clinical and microbiological characteristics of Klebsiella pneumoniae liver abscess in East China. BMC Infect Dis 15:161

4. Thomsen RW, Jepsen P, Sorensen HT (2007) Diabetes mellitus and pyogenic liver abscess: risk and prognosis. Clin Infect Dis 44 : 1194-1201

5. Tsai FC, Huang YT, Chang LY, Wang JT (2008) Pyogenic liver abscess as endemic disease, Taiwan. Emerg Infect Dis 14:1592-1600

6. Jun CH, Yoon JH, Wi JW, Park SY, Lee WS, Jung SI, Park CH, Joo YE, Kim HS, Choi SK, Rew JS (2015) Risk factors and clinical outcomes for spontaneous rupture of pyogenic liver abscess. J Dig Dis 16(1):31-36

7. Desoubeaux G, Chaussade H, Thellier M, Poussing S, Bastides F, Bailly E, Lanotte P, Alison D, Brunereau L, Bernard L, Chandenier $J$ (2014) Unusual multiple large abscesses of the liver: interest of the radiological features and the real-time PCR to distinguish between bacterial and amebic etiologies. Pathog Glob Health 108:53-57

8. Tian LT, Yao K, Zhang XY, Zhang ZD, Liang YJ, Yin DL, Lee L, Jiang HC, Liu LX (2012) Liver abscesses in adult patients with and without diabetes mellitus: an analysis of the clinical characteristics, features of the causative pathogens, outcomes and predictors of fatality: a report based on a large population, retrospective study in China. Clin Microbiol Infect 18:E314-E330 
9. Huang CJ, Pitt HA, Lipsett PA, Osterman FJ, Lillemoe KD, Cameron JL, Zuidema GD (1996) Pyogenic hepatic abscess. Changing trends over 42 years. Ann Surg 223(600-607):607-609

10. Chu KM, Fan ST, Lai EC, Lo CM, Wong J (1996) Pyogenic liver abscess. An audit of experience over the past decade. Arch Surg 131:148-152

11. Rahimian J, Wilson T, Oram V, Holzman RS (2004) Pyogenic liver abscess: recent trends in etiology and mortality. Clin Infect Dis 39: 1654-1659

12. Liu Y, Wang JY, Jiang W (2013) An increasing prominent disease of Klebsiella pneumoniae liver abscess: etiology, diagnosis, and treatment. Gastroenterol Res Pract 2013:258514

13. Siu LK, Yeh KM, Lin JC, Fung CP, Chang FY (2012) Klebsiella pneumoniae liver abscess: a new invasive syndrome. Lancet Infect Dis 12:881-887

14. Pang TC, Fung T, Samra J, Hugh TJ, Smith RC (2011) Pyogenic liver abscess: an audit of 10 years' experience. World J Gastroenterol 17:1622-1630

15. Lee JY, Kim KH (2014) Endogenous endophthalmitis complicated by pyogenic liver abscess: a review of 17 years' experience at a single center. Digestion 90:116-121

16. Fang CT, Lai SY, Yi WC, Hsueh PR, Liu KL, Chang SC (2007) Klebsiella pneumoniae genotype K1: an emerging pathogen that causes septic ocular or central nervous system complications from pyogenic liver abscess. Clin Infect Dis 45:284-293

17. Cerwenka H (2010) Pyogenic liver abscess: differences in etiology and treatment in Southeast Asia and Central Europe. World J Gastroenterol 16:2458-2462

18. Muller LM, Gorter KJ, Hak E, Goudzwaard WL, Schellevis FG, Hoepelman AI, Rutten GE (2005) Increased risk of common infections in patients with type 1 and type 2 diabetes mellitus. Clin Infect Dis 41:281-288

19. Shah BR, Hux JE (2003) Quantifying the risk of infectious diseases for people with diabetes. Diabetes Care 26:510-513

20. Foo NP, Chen KT, Lin HJ, Guo HR (2010) Characteristics of pyogenic liver abscess patients with and without diabetes mellitus. Am J Gastroenterol 105:328-335

21. Alberti KG, Zimmet PZ (1998) Definition, diagnosis and classification of diabetes mellitus and its complications. Part 1: diagnosis and classification of diabetes mellitus provisional report of a WHO consultation. Diabet Med 15:539-553

22. Higgins JP, Thompson SG, Deeks JJ, Altman DG (2003) Measuring inconsistency in meta-analyses. BMJ 327:557-560

23. Sterne JA, Egger M, Smith GD (2001) Systematic reviews in health care: Investigating and dealing with publication and other biases in meta-analysis. BMJ 323:101-105

24. Lai HC, Lin CC, Cheng KS, Kao JT, Chou JW, Peng CY, Lai SW, Chen PC, Sung FC (2014) Increased incidence of gastrointestinal cancers among patients with pyogenic liver abscess: a populationbased cohort study. Gastroenterology 146:129-137

25. Huang WK, Lin YC, Chiou MJ, Yang TS, Chang JW, Yu KH, Kuo CF, See LC (2013) Pyogenic liver abscess as a warning sign for primary liver cancer: a nationwide population-based study. Asian Pac J Cancer Prev 14:4727-4731

26. Levin KA (2006) Study design III: Cross-sectional studies. Evid Based Dent 7:24-25

27. Yang CC, Yen CH, Ho MW, Wang JH (2004) Comparison of pyogenic liver abscess caused by non-Klebsiella pneumoniae and Klebsiella pneumoniae. J Microbiol Immunol Infect 37:176-184

28. Chen SC, Yen CH, Lai KC, Tsao SM, Cheng KS, Chen CC, Lee MC, Chou MC (2005) Pyogenic liver abscesses with Escherichia coli: etiology, clinical course, outcome, and prognostic factors. Wien Klin Wochenschr 117:809-815

29. Wong VW, Cheung YS, Wong J, Lee KF, Lai PB (2010) A community-acquired methicillin-resistant Staphylococcus aureus liver abscess. Hong Kong Med J 16:227-229
30. Wu PF, Chang YY, Lin YT, Wang FD, Chan YJ, Fung CP (2015) Clinical characteristics and economic consequence of Klebsiella pneumoniae liver abscess in Taiwan. J Microbiol Immunol Infect 48:190-197

31. Fung CP, Lin YT, Lin JC, Chen TL, Yeh KM, Chang FY, Chuang HC, Wu HS, Tseng CP, Siu LK (2012) Klebsiella pneumoniae in gastrointestinal tract and pyogenic liver abscess. Emerg Infect Dis 18:1322-1325

32. Lin YT, Siu LK, Lin JC, Chen TL, Tseng CP, Yeh KM, Chang FY, Fung CP (2012) Seroepidemiology of Klebsiella pneumoniae colonizing the intestinal tract of healthy Chinese and overseas Chinese adults in Asian countries. BMC Microbiol 12:13

33. Kim JK, Chung DR, Wie SH, Yoo JH, Park SW (2009) Risk factor analysis of invasive liver abscess caused by the K1 serotype Klebsiella pneumoniae. Eur J Clin Microbiol Infect Dis 28:109-111

34. Zuo H, Shi Z, Hussain A (2014) Prevalence, trends and risk factors for the diabetes epidemic in China: a systematic review and metaanalysis. Diabetes Res Clin Pract 104:63-72

35. Chen SC, Yen CH, Tsao SM, Huang CC, Chen CC, Lee MC, Bell WR (2005) Comparison of pyogenic liver abscesses of biliary and cryptogenic origin. An eight-year analysis in a University Hospital. Swiss Med Wkly 135:344-351

36. Keynan Y, Rubinstein E (2007) The changing face of Klebsiella pneumoniae infections in the community. Int J Antimicrob Agents 30:385-389

37. Du Y, Luo J, Wang C, Wen Q, Duan M, Zhang H, He H (2014) Detection of drug-resistant Klebsiella pneumoniae in Chinese hares (Lepus sinensis). J Wildl Dis 50:109-112

38. Zhang Y, Zeng J, Liu W, Zhao F, Hu Z, Zhao C, Wang Q, Wang X, Chen H, Li H, Zhang F, Li S, Cao B, Wang H (2015) Emergence of a hypervirulent carbapenem-resistant Klebsiella pneumoniae isolate from clinical infections in China. J Infect 7:553-560

39. Li W, Sun G, Yu Y, Li N, Chen M, Jin R, Jiao Y, Wu H (2014) Increasing occurrence of antimicrobial-resistant hypervirulent (hypermucoviscous) Klebsiella pneumoniae isolates in China. Clin Infect Dis 58:225-232

40. Tzouvelekis LS, Markogiannakis A, Psichogiou M, Tassios PT, Daikos GL (2012) Carbapenemases in Klebsiella pneumoniae and other Enterobacteriaceae: an evolving crisis of global dimensions. Clin Microbiol Rev 25:682-707

41. Shon AS, Bajwa RP, Russo TA (2013) Hypervirulent (hypermucoviscous) Klebsiella pneumoniae: a new and dangerous breed. Virulence 4:107-118

42. Lin YC, Lu MC, Tang HL, Liu HC, Chen CH, Liu KS, Lin C, Chiou CS, Chiang MK, Chen CM, Lai YC (2011) Assessment of hypermucoviscosity as a virulence factor for experimental Klebsiella pneumoniae infections: comparative virulence analysis with hypermucoviscosity-negative strain. BMC Microbiol 11:50

43. Chen SC, Lee YT, Lai KC, Cheng KS, Jeng LB, Wu WY, Chen CC, Lee MC (2006) Risk factors for developing metastatic infection from pyogenic liver abscesses. Swiss Med Wkly 136:119-126

44. Chen SC, Tsai SJ, Chen CH, Huang CC, Lin DB, Wang PH, Chen CC, Lee MC (2008) Predictors of mortality in patients with pyogenic liver abscess. Neth J Med 66:196-203

45. Lee SS, Chen YS, Tsai HC, Wann SR, Lin HH, Huang CK, Liu YC (2008) Predictors of septic metastatic infection and mortality among patients with Klebsiella pneumoniae liver abscess. Clin Infect Dis 47:642-650

46. Zwahlen M, Renehan A, Egger M (2008) Meta-analysis in medical research: potentials and limitations. Urol Oncol 26:320-329

47. Egger M, Davey SG, Schneider M, Minder C (1997) Bias in metaanalysis detected by a simple, graphical test. BMJ 315:629-634

48. Begg CB, Mazumdar M (1994) Operating characteristics of a rank correlation test for publication bias. Biometrics 50:1088-1101 